\title{
ANALYSIS OF GROUND-TRANSDUCER COUPLING IN MONITORING VIBRATION FROM RAILWAYS: A CASE STUDY
}

\author{
G. ALFARO DEGAN, G. COLTRINARI \& D. LIPPIELLO \\ Department of Engineering, University of Roma Tre, Rome, Italy.
}

\begin{abstract}
Monitoring railway-induced ground vibrations represents a fundamental step in assessing the environmental impact of train passage on buildings and surrounding receptors. For this purpose, accurate measurements of seismic waves are often required. Nevertheless, depending on soil structure, its characteristics or surface, the placement of transducer may affect the shape and phase of the seismic wave determining signal distortion and finally affecting the measurement itself. In particular, the most critical aspect of the sampling phase is represented by the coupling between the seismic transducer and the soil. Slipping or friction of the transducer may generate unacceptable results. For this purpose, different methods of coupling were tested in different conditions with regard to high speed train passages near a location in Rome. To start the test, some steel spikes of different shapes and lengths were tested in order to investigate their response to ground characteristics, surface and resonance frequency. The sampling campaign was carried out by fastening the transducers on the spikes fixed vertically in the soil at a certain distance from the railway track. Sampled data consisting of each passage in Peak Particle Velocity and acceleration were compared with those obtained by coupling transducers as defined in UNI 9916 norms. According to this norm, sensors are buried into the soil at a fixed depth depending on their dimensions. The final part of the sampling is aimed at comparing the sets of obtained values. This analysis is focused on the identification of those parameters to be taken into account in order to select the best coupling method for different conditions.
\end{abstract}

Keywords: ground transducer coupling, railways, seismic waves, vibration.

\section{INTRODUCTION}

Ground vibrations induced by railway traffic have received particular attention in recent years since they may generate adverse effects both on people in the surroundings and on adjacent buildings or structures (Alfaro Degan et al. [1]). Nevertheless, the energetic efficiency of railway transportation, together with the related improvement of traffic conditions and the reduction of airborne pollutant emissions, has determined a huge implementation of new railway lines. This development has caused a growing interest among the scientific community for the environmental effects due to the passage of trains. In particular, many research studies about noise and vibration have been carried out in terms of both measurement techniques (Kurzweil [2]; Kima [3]) and analytical methods (Alfaro Degan et al. [4]). Moreover, efforts have been made in order to improve passengers' comfort by reducing vibrations perceived in the vehicle, but the issue of railway-induced ground vibration is far from being solved (Ryue [5]; Adam [6]; Zoccali [7]). Because many parameters affect this phenomenon, different approaches of growing complexity have been proposed to model vibrations determined by train passage (Costa [8]). Among the main causes of uncertainty in modelling train-induced waves, the different transmission paths along the

This paper is part of the proceedings of the 22nd International Conference on Urban Transport and the Environment (Urban Transport 2016)

www.witconferences.com
} 
three directions in a fundamentally inhomogeneous medium (Nejati [9]) constitute the most relevant one. Many researchers have focused their efforts on performing prediction models (Ju [10]; Triepaischajonsak [11]; Lui [12]), whereby the propagation of ground vibration waves is analysed considering different generation mechanisms such as rail deflection and track irregularity rather than vehicle dynamics (Volberg [13]). Moreover, the validation of propagation models performed by field tests (Connolly [14]) has highlighted some further features connected with sampling methods. In particular, in order to achieve good measurements, two relevant aspects are represented by positioning and ground-coupling transducer. An efficient coupling between the transducer and the ground is often difficult to achieve, especially when the transducer mounting options are restricted to those allowed by local ground conditions. A bad coupling may be represented by the slipping of the transducer, thus leading to signal distortion in amplitude and phase. This fact consequently implies that vibration levels are erroneously measured. On the contrary, an efficient ground transducer coupling is guaranteed by a good adherence to sampling tests.. Scientific literature reveals that the ground coupling is a resonant phenomenon in which the transducer and ground coupling create a resonant system (Washburn [15]). This feature has been investigated by several studies focused on the parameters influencing the resonance frequency. The base area and the weight of the transducer together with the ground conditions have been found to be among the most important parameters that affect the amplitude and the phase of the signal (Omata [16]). Another study concluded that the length of the section, the positioning of the transducer and the characteristics of the soil affect the measurements in a deeper way (Krohn [17]). Research based on theoretical models and results from laboratory tests can describe transducer ground coupling in a limited way because the boundary conditions of field tests are very complex to be replicated. In particular, since soil properties, density gradients, quality of mounting and so forth (Faber [18]) vary from one case to another, field validation represents the only way to test, at the local scale, the efficiency of any model. In order to suggest good practices in ground transducer coupling, many national institutions have developed specific documents or technical norms (UNI 9916 [19]; BSI [20],) in which the recommended solution was that of fixing the instrument. This approach was found to be effective especially when the maximum sampled acceleration falls in the interval between $0.2 \mathrm{~g}$ and $1.0 \mathrm{~g}$ (Segarra [21]). Another coupling method is performed with the use of steel spikes. Their effectiveness is, however, largely debated. Some researchers claim that this method modifies the recorded ground motion (Dowding [22]), thus contributing to overestimation of the real value by $46.5 \%$ (Blair [23]). Other studies highlight that the above method shows good results for accelerations below 1.0g (ISEE [24]). Moreover, long steel spikes are probably the cause for increasing the coupling resonance frequency. This point of view is not shared by some authors who instead have shown by means of a specific model that the resonant frequency decreases by increasing length and radius of the spike section (Drijkoningen [25]). Another simple way to perform the coupling of the transducer to the soil is the use of a weight placed on the top of the instrument. Also, this method appears to be effective (Stagg [26]) in some cases (acceleration values less than $1 g$ ) although its application may not be considered affordable under other conditions (Robertson [27]). Such an overview of the scientific literature reveals a lack of a shared approach to the ground transducer coupling. In this article, a case study is presented in which two different sampling methods are tested. The obtained results are compared and finally some considerations are carried out on the most effective solution for the selected case study. 


\section{MATERIAL AND METHODS}

This work aims to compare different methods in order to measure ground vibrations induced by train passages. A metal cube and steel spikes were employed. These spikes are characterized by different lengths and an 'L' shape, according to field-guidelines UNI 5783-66. In order to investigate some of the issues mentioned above, the adopted methodology consisted in considering the actual signal input as unknown (vibration induced by train impinging on the mounting system). The effectiveness of each coupling method was then assessed by feeding the same impulse into the mounted transducers. This was an effective way of investigating if there were internal flaws or relevant differences in the structure (e.g., resonances) where the transducers were placed (Fig.1).

A square metal plate of 5-mm thickness was welded on each steel spike. The transducer was fixed on it through a permanent magnet. Table 1 shows the technical characteristics.

\subsection{Sampling device}

The sampling campaign was carried out by mean of a tri axial accelerometer whose characteristics are summarized in Table 2. The signal has been acquired through SAMURAI

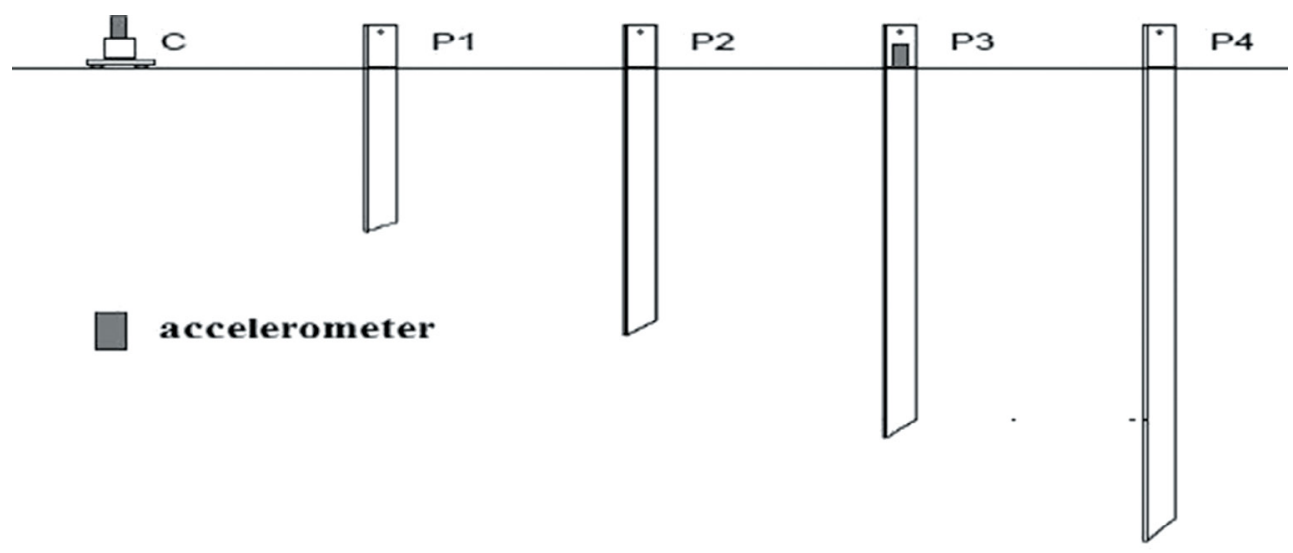

Figure 1: Accelerometer on metal cube and steel spikes.

Table 1: Characteristics of steel spikes.

\begin{tabular}{lrrrc}
\hline Spike & Weight, $\mathrm{kg}$ & Length, $\mathrm{mm}$ & Thickness, $\mathrm{mm}$ & Plate area, $\mathrm{mm}^{2}$ \\
\hline P1 & 1.9 & 500 & 5 & 2,025 \\
P2 & 2.8 & 750 & 5 & 2,025 \\
P3 & 3.8 & 1,000 & 5 & 2,025 \\
P4 & 4.7 & 1,250 & 5 & 2,025 \\
\hline
\end{tabular}

Table 2: Characteristics of the instruments and measurement parameters.

\begin{tabular}{lccc}
\hline Transducer & Sensitivity, $\mathrm{mV} /\left(\mathrm{m} / \mathrm{s}^{2}\right)$ & Sampling frequency, Hz & Gain, V \\
\hline $\begin{array}{l}\text { Tri-axial accelerometer } \\
\text { PCB 393A03 }\end{array}$ & 10.55 & 1,250 & 3.15 \\
\hline
\end{tabular}




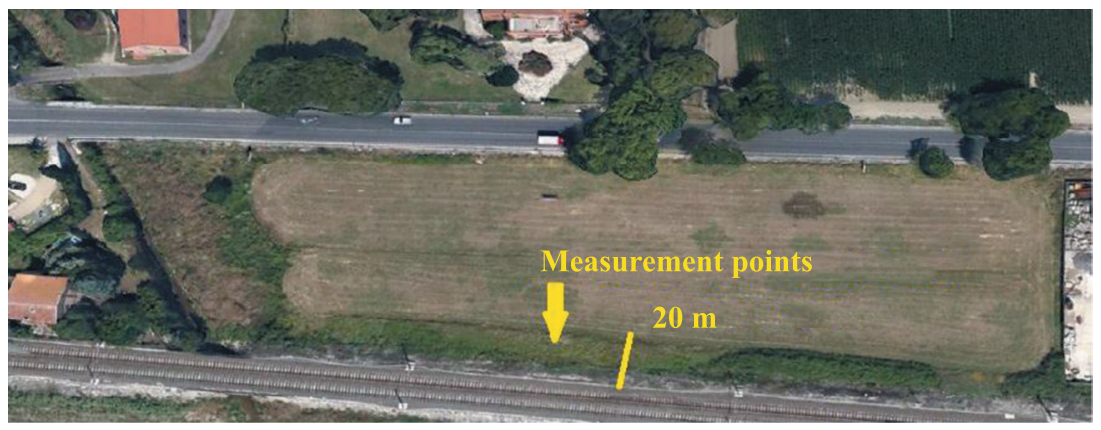

Figure 2: Measurement points.
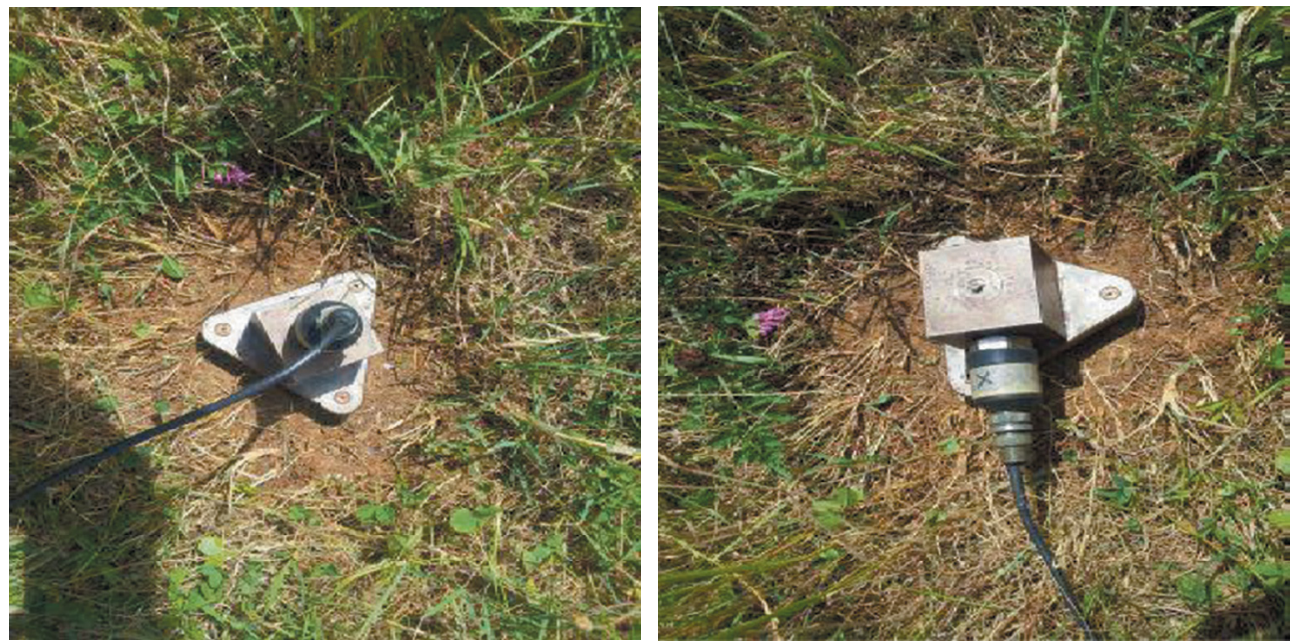

Figure 3: Accelerometer fixed on metal cube.

software and analysed with Noise Vibration Work software. The instrument was calibrated with $1,250 \mathrm{~Hz}$ sampling frequency and $3.15 \mathrm{~V}$ gain.

Strict adherence to the correct alignment of the transducer in the ground is very important in order to obtain correct measurement; an incorrect alignment may affect the measurement itself. The accelerometer should be positioned on an orthogonal plane with respect to the ground surface. Krohn [17] shows that at frequencies lower that $60 \mathrm{~Hz}$, the vertical alignment of the transducer contributes to creation of a distortion greater than that generated by the coupling mechanism. Before each field test, the vertical and horizontal alignments with respect to the ground were verified through a bubble level placed on the transducer.

\subsection{Measurement campaigns}

The site consisted of a railway section in the southern part of Rome (see Fig. 2). The sampling points were located at a distance of $20 \mathrm{~m}$ at a lower level with respect to the railway (approximately $3 \mathrm{~m}$ ). Three distinct tests were carried out to set the instruments; the first one was aimed to sample the component of the signal along each axis; the second and the third one were used to record vibration levels through steel spikes. 


\subsubsection{First measurement campaign}

The first measurement campaign was carried out in order to assess the most stressed direction. The passage of 20 trains was recorded. Measurements were carried out by means of three accelerometers fixed on the metal cube and connected to a Sound-Book channel. The instruments were positioned, in all measurement campaigns, according to the same standard reference system: $x$-axis $=$ perpendicular to rails (longitudinal), $y$-axis $=$ orthogonal to $x$-axis (transversal), $z$-axis = perpendicular to the ground (vertical). The results showed that $z$ - and $x$-axes were the most stressed (Fig. 3).

\subsubsection{Second measurement campaign}

In the second measurement campaign, a comparison between the steel spikes P1, P2 (see Fig. 1) and metal cube was carried out. The simultaneous acquisition of data along different axes was carried out by means of three accelerometers in order to evaluate different responses of each transducer-ground coupling. In particular, the first accelerometer was attached on the metal cube. The remaining two accelerometers were used to measure the vibrations through steel spikes. Initially all transducers were fixed along $x$-direction and later along $z$-direction.

\subsubsection{Third measurement campaign}

The experimental methodology and arrangement of steel spikes were consistent with second measurement campaign. The only difference was represented by changing the length of steel spikes (P3 and P4; see Table 1). Data acquisition was performed as shown in Fig. 4 and under the same ground conditions of the previous campaigns.

\section{RESULTS}

The following sections discuss graphs that show the results obtained in the measurement campaigns. As previously described, data are divided for the purpose of pointing out characteristics of each transducer-ground coupling.
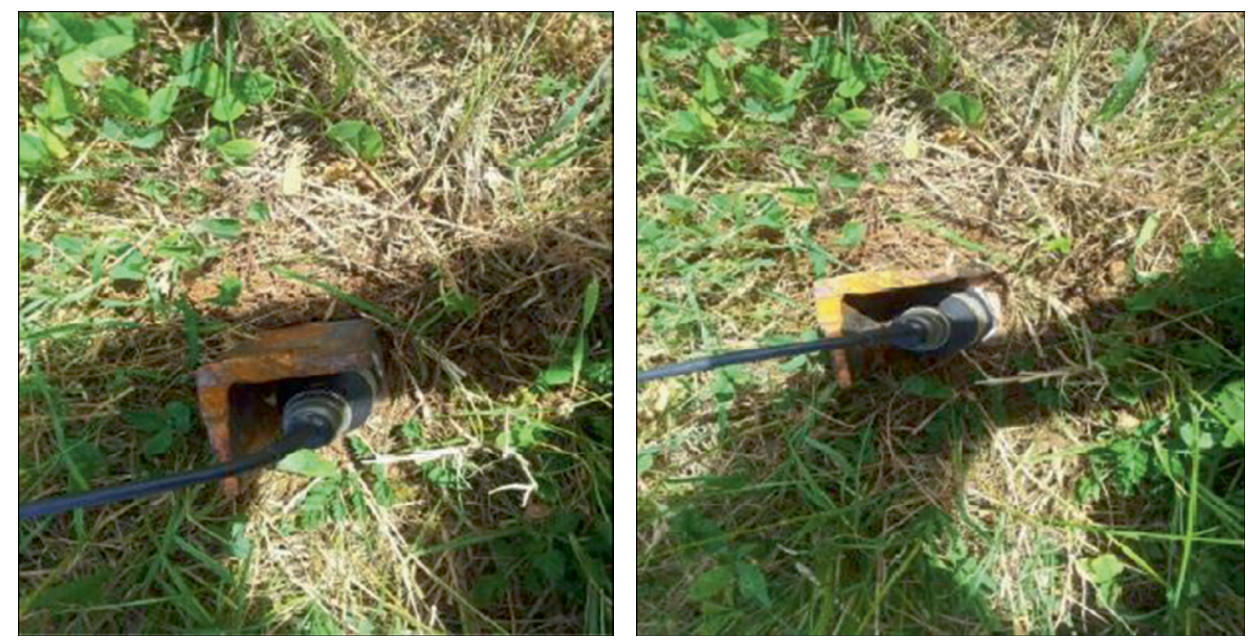

Figure 4: Accelerometer fixed on steel spikes. 


\subsection{First campaign}

In Figs. 5-7, the results, expressed in terms of $\mathrm{dB}$ from accelerometers fixed on metal cube are presented. Data are referred to each axis.

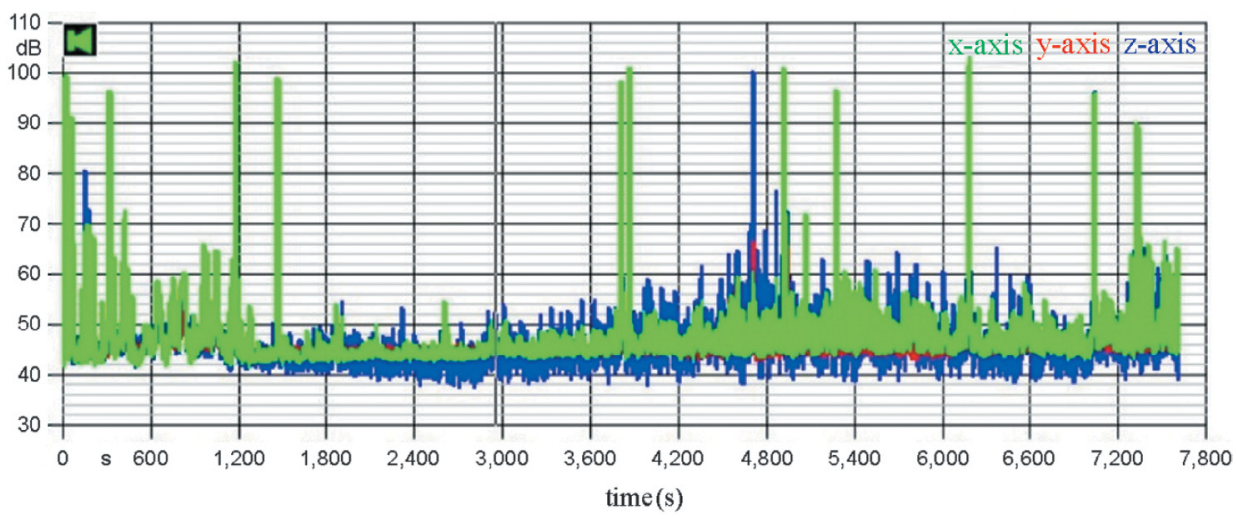

Figure 5: Acceleration data recorded from first measurement campaign.

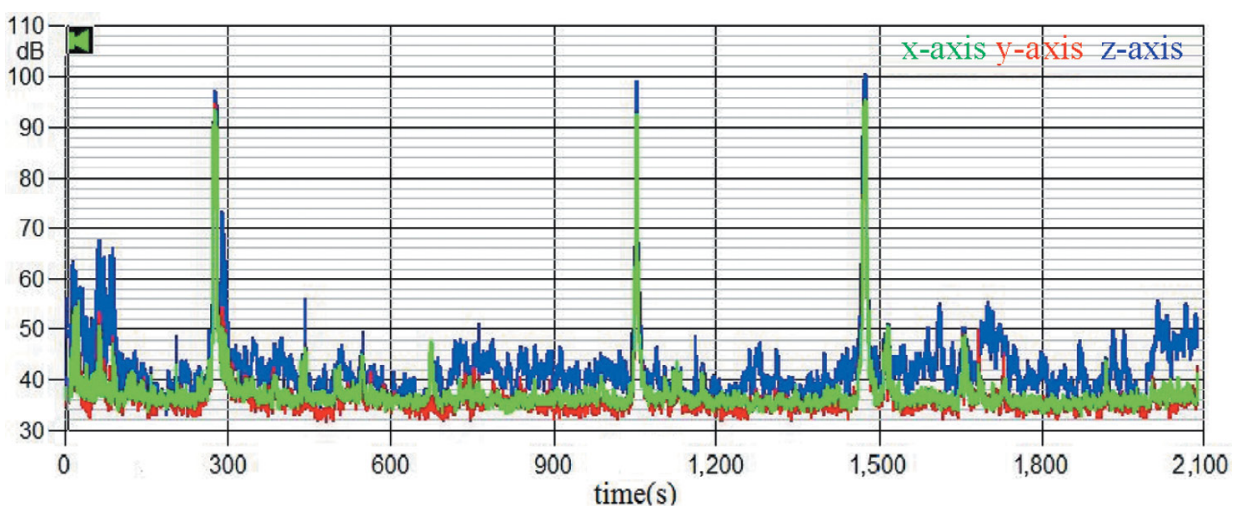

Figure 6: Time history recorded from first measurement campaign.

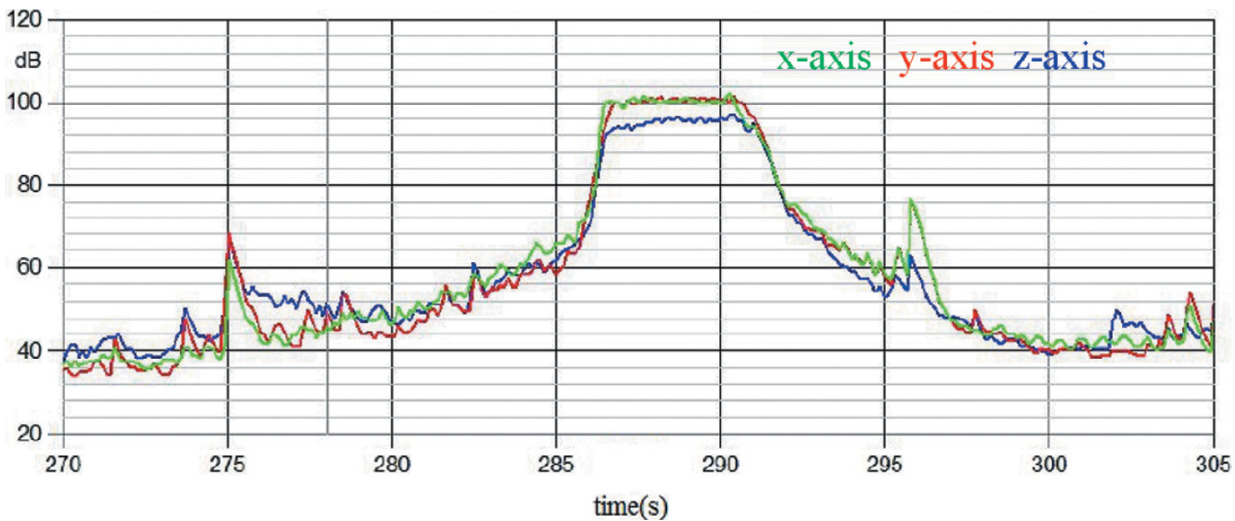

Figure 7: Analysis of a specific train passage. 


\subsection{Second campaign}

Results from the second campaign are shown in Figs. 8 and 9. The graphs show the comparison between metal cube and steel spikes $\mathrm{P} 1$ and $\mathrm{P} 2$ with $1 / 3$ octave band histograms.

\subsection{Third campaign}

The following graphs are referred to the third campaign with P3 and P4 steel spikes (Fig. 10).

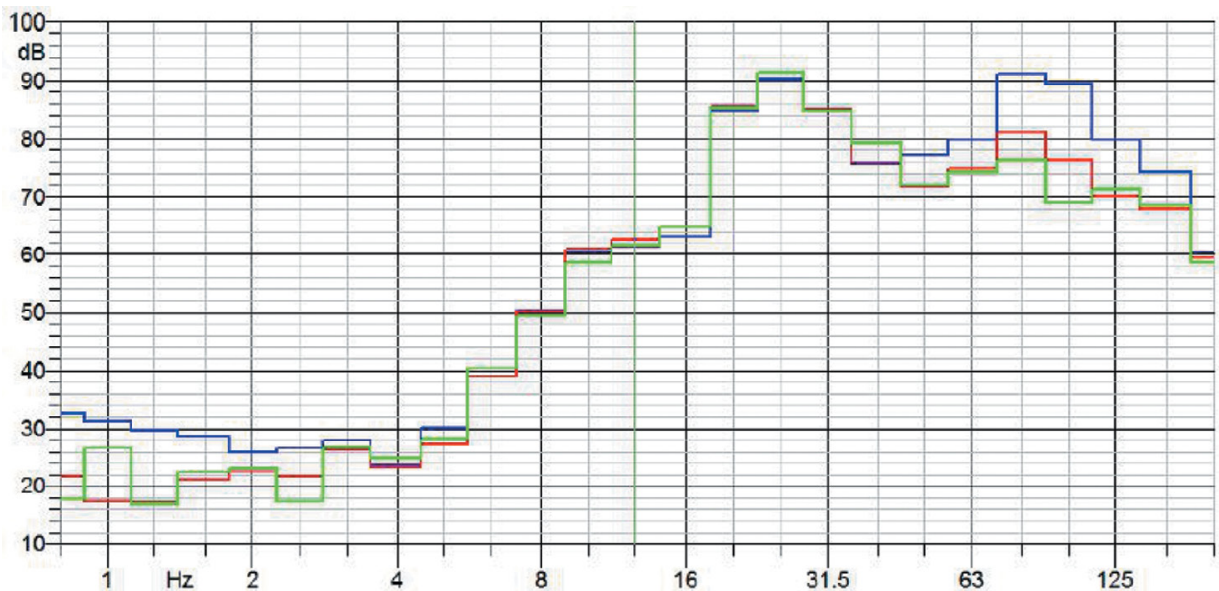

Figure 8: Frequency spectrum of metal cube (blue), P1(green) and P2 (red) steel spikes along the $\mathrm{x}$-axis.

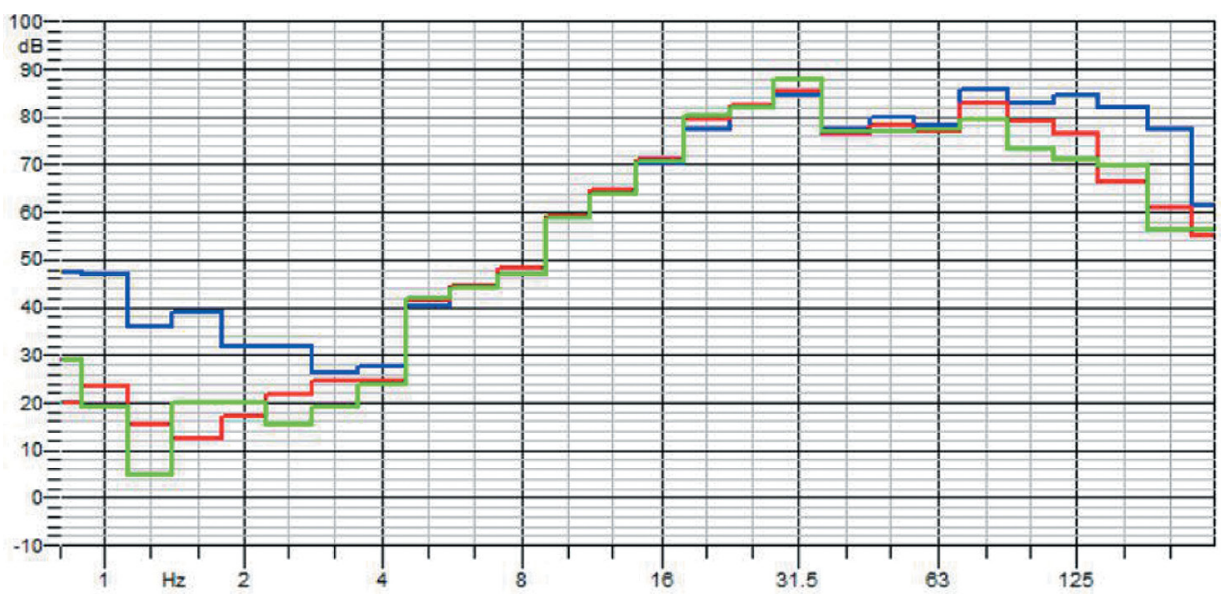

Figure 9: Frequency spectrum of metal cube (blue), P1 (green) and P2 (red) steel spikes along the z-axis. 


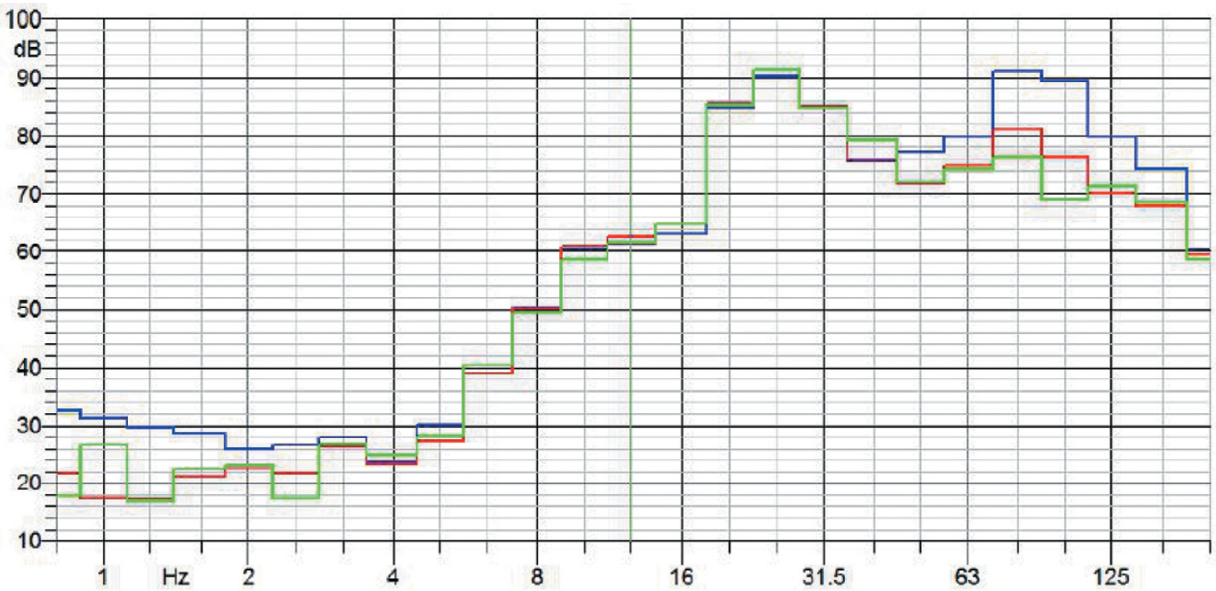

Figure 10: Frequency spectrum of metal cube (blue), P3 (green) and P4 (red) steel spikes along the $x$-axis.

\section{DISCUSSION}

The present study was carried out on the basis of four principal points. Firstly, each train passage was identified in time-history measurement (see Fig. 7). The transient time period was circumscribed when the sampled signal appeared approximately to reach a constant value. So, starting from this instant the equivalent level and the frequency spectrum were assessed. Then, in order to point out different responses from different steel spikes, a numerical analysis was realized with MATLAB software. In particular, for each train passage, the difference, along $x$ - and $z$-axes, between the signals from the accelerometer fixed on metal cube and that from each steel spikes was calculated. Finally the average value of these differences was calculated taking into account each of the 20 train passages. In Fig. 11, a comparison among average vibration levels for all train passages is shown along the $x$-axis. The analogous data referred to the $z$-axis are shown in Fig. 12.

An outcome of the findings was that the values obtained by means of metal cube (blue line) are greater than those of steel spikes (red and green line) in the frequency range below 4 $\mathrm{Hz}$ and in the interval between 50 and $100 \mathrm{~Hz}$. But, on analysing the central frequency range (4-40 Hz), the four sets of data appear very similar to an anomalous position of over 125 Hz. Another finding was that the $z$-axis was not always the most stressed one, as horizontal vibrations along the $x$-axis were found to be of the same intensity. This aspect is relevant for choosing the type of ground transducer coupling. Finally, steel spikes show a higher response in the high frequency range (see Figs. 11 and 12): P3 and P4 spikes along the $z$-direction while P1 and P2 spike along the $x$-direction. The higher levels recorded at high frequencies $(120 \mathrm{~Hz})$ may be determined by different resonance frequencies. In fact, metal cubes showed a resonance frequency at the centre of the analysed band. On the contrary, the resonance frequency of steel spikes seemed not to fall in this range.

\section{CONCLUSIONS}

The obtained results suggest some considerations of the advantages and limitations of the presented coupling methods. The first difference is represented by the accuracy required to install the devices. If, on the one hand, the metal cube is only to be leaned on the ground, on the other 


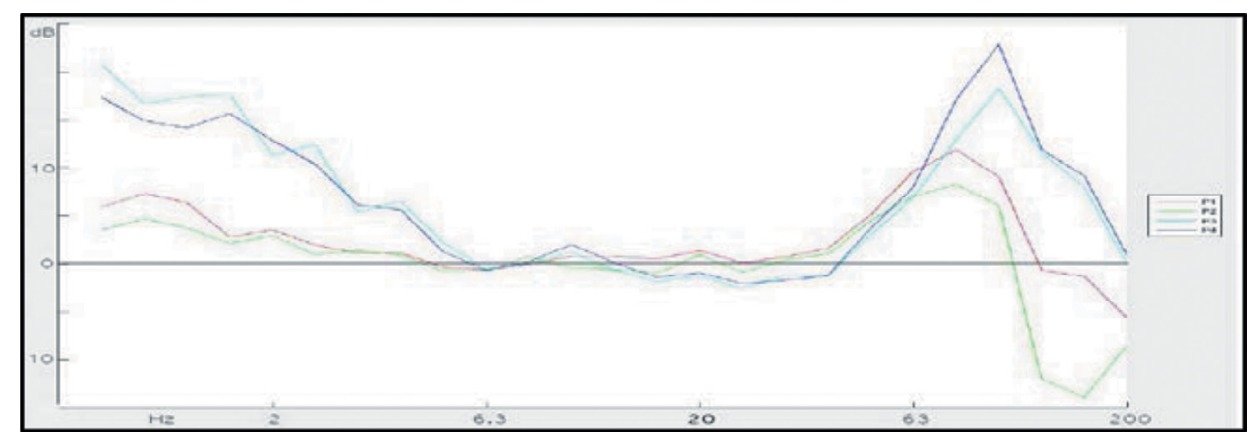

Figure 11: Comparison between steel spikes along the $x$-axis $(\mathrm{P} 1=$ red, $\mathrm{P} 2=$ green, P3 = blue, $\mathrm{P} 4$ = violet).

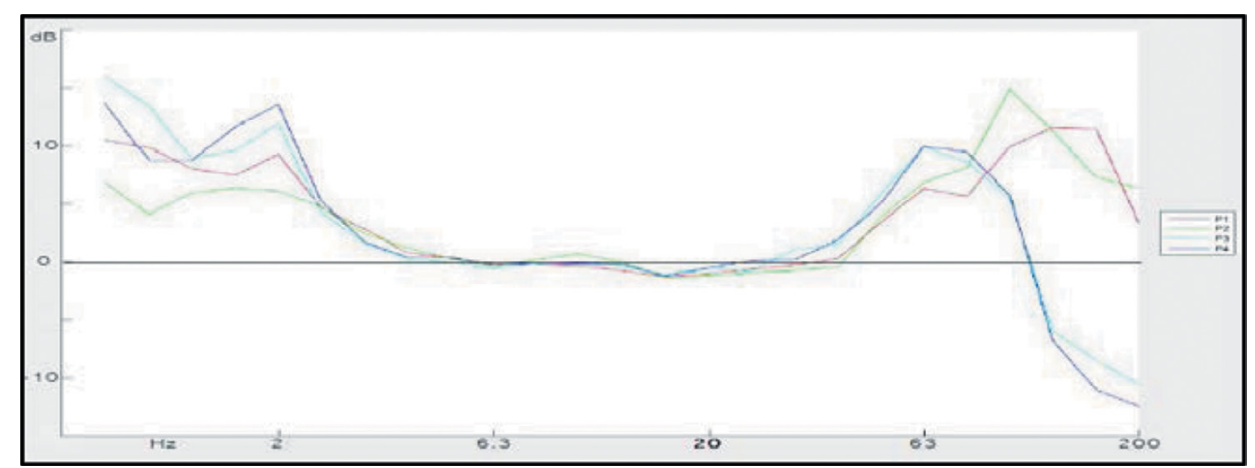

Figure 12: Comparison between steel spikes along the $z$-axis $(\mathrm{P} 1=$ red, $\mathrm{P} 2=$ green, P3 = blue, P4 = violet).

hand, the spike method is more complex because it requires the insertion of the spikes themselves in the ground. Since this procedure is generally performed by means of hammers, it may generate undesirable deformation of the supports with a consequent signal distortion. To avoid this, further preliminary tests are necessary to set the devices on the ground. On analysing the frequency spectrum, a relevant outcome is that the two methodologies return different results. In particular, the measurements from the metal cube show higher values at lower frequencies when compared with those from steel spikes. This fact may be attributed to the so-called thermal noise. In particular, the contact area between the sampling support and the ground varies depending on the shape of the support itself. In particular, the steel spikes contact area is wider than that of the metal cube area and therefore heat dissipation is more consistent. Since transducer performances are affected by the temperature of the support, an overestimation of values from the metal cube may be observed at lower frequencies. Although it requires more applications this result may be considered as a general outcome. Finally, it appears that along the $z$-axis the length of steel spikes influences the signal in the high frequency range. This data may be highlighted by observing that the more the spike length increases the more the sampled value tends to increase. The results obtained in this study encourage further research in order to verify the validity of these methods. In particular, a further measurement campaign is in progress to analyse the influence of length of steel spikes. 


\section{REFERENCES}

[1] Alfaro Degan, G., Coltrinari, G. \& Lippiello, D., Urban tram induced vibrations: Real time monitoring of historical buildings in the centre of Rome. Proceedings of the 15th International Multidisciplinary Scientific GeoConference Surveying Geology and Mining Ecology Management, SGEM 2015, Albena, Bulgaria, 1(5), pp. 1031-1038, 2015. DOI: 10.5593/SGEM2015/B51/S20.137.

[2] Kurzweil, L.G., Ground-borne noise and vibration from underground rail systems. Journal of Sound and Vibration, 66(3), pp. 363-370, 1979. DOI: 10.1016/0022460X(79)90853-8.

[3] Kima, D.S. \& Lee, J.S., Propagation and attenuation characteristics of various ground vibrations. Soil Dynamics and Earthquake Engineering, 19, pp. 115-126, 2000. DOI: 10.1016/S0267-7261(00)00002-6.

[4] Alfaro Degan G., Lippiello D., Lorenzetti S. \& Pinzari M., Vibration assessing models: Comparison between methods. WIT Transactions on Biomedicine and Health, WIT Press, 2013, ISSN: 1743-3525, 16, pp. 59-69, DOI: 10.2495/EHR130061.

[5] Ryue, J. et al., Investigations of propagating wave types in railway tracks at high frequencies. Journal of Sound and Vibration, 315(1), pp. 157-175, 2008. DOI: 10.1016/j. jsv.2008.01.054.

[6] Adam, M. \& Von Estorff, O., Reduction of train-induced building vibrations by using open and filled trenches. Computers \& Structures, 83(1), pp. 11-24, 2005. DOI: 10.1016/j.compstruc.2004.08.010.

[7] Zoccali, P., Cantisani, G. \& Loprencipe, G., Ground-vibrations induced by trains: Filled trenches mitigation capacity and length influence. Construction and Building Materials, 74, pp. 1-8, 2015. DOI: 10.1016/j.conbuildmat.2014.09.083.

[8] Costa, P.A., Critical speed of railway tracks. Detailed and simplified approaches. Transportation Geotechnics, 2, pp. 30-46, 2015. DOI: 10.1016/j.trgeo.2014.09.003.

[9] Nejati, H.R., Morteza A. \& Hashemolhosseini, H., Numerical analysis of ground surface vibration induced by underground train movement. Tunnelling and Underground Space Technology, 29, pp. 1-9, 2012. DOI: 10.1016/j.tust.2011.12.006.

[10] Ju, S.H., Ho, Y.S. \& Leong, C.C., A finite element method for analysis of vibration induced by maglev trains. Journal of Sound and Vibration, 331, pp. 3751-3761, 2012. DOI: $10.1016 /$ j.jsv.2012.04.004.

[11] Triepaischajonsak, N. \& Thompson, D.J., A hybrid modelling approach for predicting ground vibration from trains. Journal of Sound and Vibration, 335, pp. 147-173, 2015. DOI: $10.1016 /$ j.jsv.2014.09.029.

[12] Lui, W.K. et al., A comparative study of different numerical models for predicting train noise in high-rise cities. Applied Acoustics, 67, pp. 432-449, 2006. DOI: 10.1016/j. apacoust.2005.08.005.

[13] Volberg, G., Propagation of ground vibrations near railway tracks. Journal of Sound and Vibration, 87(2), pp. 371-376, 1983. DOI: 10.1016/0022-460X(83)90576-X.

[14] Connolly, D.P. et al., Field testing and analysis of high speed rail vibrations. Soil Dynamics and Earthquake Engineering, 67, pp. 102-118, 2014. 10.1016/j.soildyn.2014.08.013

[15] Washburn, H. \& Wiley, H., The effect of the placement of a seismometer on its response characteristics. Geophysics, 6, pp. 116-131, 1941. DOI: 10.1190/1.1443713.

[16] Omata, S., Ground couplings and measurement frequency ranges of vibration transducers. Journal of the Acoustical Society of America, 73(6), pp. 2187-2192, 1983. DOI: 10.1121/1.389543. 
[17] Krohn, C.E., Geophone ground coupling. Geophysics, 49(6), pp. 722-731, 1984. DOI: 10.1190/1.1441700.

[18] Faber, K., Maxwell, P.W. \& Edelmann, H.A.K. Recording reliability in seismic exploration as influenced by geophone-ground coupling. 56th Meeting of the EAEG, Vienna, 1994.

[19] UNI 9916, Criteria for the measurement of vibrations and the assessment of their effects on buildings, 2004.

[20] BSI, British Standards Institution. BS 7385-1: Evaluation and measurement for vibration in buildings, Part 1: Guide for measurement of vibrations and evaluation of their effects on buildings, London, 1990.

[21] Segarra, P., Sanchidrián, J.A., Castedo, R., López, L.M. \& del Castillo, I., Performance of some coupling methods for blast vibration monitoring. Journal of Applied Geophysics, 112, pp. 129-135, 2015. DOI: 10.1016/j.jappgeo.2014.11.012.

[22] Dowding, C.H., Suggested method for blast vibration monitoring. International Journal of Rock Mechanics and Mining Sciences \& Geomechanics, 29(2) pp. 145-156, 1992. DOI: 10.1016/0148-9062(92)92124-U.

[23] Blair, D.P., Blast vibration in soil and on large resonant structure. Explo'95, Conference. Brisbane, Australia, pp. 317-322, September 1995.

[24] ISEE, Field Practice Guidelines for Blasting Seismographs, USA, 2009.

[25] Drijkoningen, G.G., Rademakers, F., Slob, E.C. \& Fokkema, J.T., A new elastic model for ground coupling of geophones with spikes. Geophysics, 71(2), pp. Q9-Q17, 2006. DOI: 10.1190/1.2187777.

[26] Stagg, M.S. \& Engler, A.J., Measurement of Blast-induced Ground Vibrations and Seismograph Calibration, US Bureau of Mines (RI 8506), 1980.

[27] Robertson, D.A., The neglected step to accurate blast monitoring: Proper coupling. 9th Annual Symposium on Explosives and Blasting Research, ISEE, January-February, San Diego, pp. 83-98. 